\title{
Hyperspectral Sensing for Assessing Nearshore Water Quality Conditions of Hudson/Raritan Estuary
}

\author{
S. Bagheri* and T. Yu \\ Department of Civil \& Environmental Engineering, New Jersey Institute of Technology, Newark, NJ 07102, USA
}

Received 1 September 2006; revised 11 July 2007; accepted 1 January 2008; published online 30 May 2008

\begin{abstract}
This study addresses the use of remote sensing hyperspectral data acquired by NASA/Airborne Visible Infra Red Imaging Spectrometer (AVIRIS) to estimate concentrations of optical water quality parameters in the Hudson/Raritan Estuary of New York-New Jersey. Hudson/Raritan estuary is a complex estuarine system where tidal and wind-driven currents are modified by freshwater discharges from the Hudson, Raritan, Hackensack, and Passaic rivers. Hypersectral (high resolution) remote sensing data offers unique advantages for the study of recurrent hydrological phenomena on regional and local scales. The paper describes the bio-optical water quality model constructed linking the water constituent concentrations to (i) the inherent optical properties (IOPs), using the specific inherent optical properties (SIOP), and (ii) to the subsurface light levels. Generation of accurate reflectance $\mathrm{R}(0)$ from radiance recorded by the AVIRIS is the key parameter for input into inverse modeling for estimation of constituent concentrations. In conjunction with bio-optical model, the linear matrix inversion technique is used for retrieval of estuarine water constituents in terms of chlorophyll, colored dissolved organic matter and inorganic material. The long term goal is to establish a monitoring/ management system for retrieval of estuarine water constituents using remotely sensed data. Such efforts are complementary to the development of spectral library for detection/identification of harmful algal blooms (HABs) causing eutrophication and pollutions in the world's coastal and estuarine waters. Results of AVIRIS data analyses in forms of thematic maps of concentrations of water quality parameters can be integrated into the Geographic Information Systems (GIS) of the estuary. GIS is a computer -based geospatial database which can be used as a management tool for monitoring of water quality conditions of the estuary.
\end{abstract}

Keywords: AVIRIS, biooptical, estuarine, eutrophication, IOP, harmful algae bloom (HABs), hyperspectral, inverse modeling, retrieval, spectroradiometer

\section{Introduction}

The Hudson/Raritan Estuarine waters of New York-New Jersey are enriched by increased nutrient loading from point and non-point sources such as agricultural and urban run-offs (e.g. agricultural herbicides, toxic discharges, suspended sediments and nutrients), causing eutrophication and pollution. Harmful algal blooms (HABs) pose a serious threat to ecosystems and public health, as well as to the economy, as they are responsible for fish kills, shellfish poisoning, and human illness. Negative impacts of these exceptional blooms as opposed to the annual spring blooms are associated with the presence of toxins secreted by various species of dinoflagellates diatoms and cyanobacteria (Pearce, 1988). While reports of toxic outbreaks are escalating worldwide, early detection remains elusive, impeding progress towards understanding the forces responsible for bloom initiation, development and advection. With increasingly sophisticated sensors, better data,

\footnotetext{
${ }^{*}$ Corresponding author. Tel.: +1 973 5962470; fax: +1 9735965790.

E-mail address: bagheri@adm.njit.edu (S. Bagheri).
}

ISSN: 1726-2135 print/1684-8799 online

(C) 2008 ISEIS All rights reserved. doi:10.3808/jei.200800116 and improved algorithms, phytoplankton detection and species identification can be accurately determined using remote sensing data. Remotely sensed data give information on the interaction between solar radiation, sea water and the different substances contained within it. The main processes involved are absorption, scattering and transmission of electromagnetic energy (Aguirre-Gomez et al., 1995). Absorption of light within the marine environment is carried out by four different components: the water itself, phytoplankton, color dissolve organic matter (CDOM) and tripton or total suspended matter (TSM). In this paper we utilized bio-optical (forward) model in conjunction with retrieval (inverse) model to derive important water properties (i.e., chlorophyll-a) using NASA/AVIRIS (Airborne Visible Infra Red Imaging Spectrometer) complemented by in-situ measurements.

\section{Study Area}

The study area is the Hudson/Raritan Estuary, which is located south of the Verrazano Narrows and bordered by western Long Island, Staten Island and New Jersey (Figure 1). The estuary is a typical partially mixed drowned river estuary (Oey et al., 1985) and it is relatively shallow $(<8 \mathrm{~m})$. The slow estimated flushing time of the estuary, 16 to 21 days or 
32 to 42 tidal cycles (Jeffries, 1962), tends to retain pollutants entering the system and delay dilution with receiving waters. The Hudson/Raritan Estuary is a complex ecosystem that is important to the New York metropolitan area and is considered "the most intensively developed and industrialized estuary on the U.S. east coast" (Pearce, 1988). Many organisms continue to use the estuary for part or all of their lives. These organisms include commercially valuable shellfish and finfish and lower organisms such as polychaetes, phytoplankton and zooplankton that are essential to the estuarine food web. Over the last century the quality of the estuarine water has degraded in part due to eutrophication, which disrupts the pre-existing natural balance of the system, resulting in phytoplankton blooms of both increased frequency and intensity in response to the over-enrichment. Noxious phytoplankton blooms are among the potential negative impacts, as are shifts to less desirable species of phytoplankton, diminished aesthetics, and changes in phytoplankton cell size. Dense and accelerated phytoplankton blooms ultimately increase oxygen demand on the system leading to episodes of hypoxia (Pearce, 1988).

The estuary is used for many recreational activities including swimming, boating and sport fishing, which are now one of the biggest industries of the area. Currently, the harmful algal blooms are documented as major contributors for shellfish bed closures, public health reports of noxious aerosols, aquatic mortality events and environmental conditions. It is imperative, because of the damage to aquatic ecosystems, fisheries and tourism, that the environmental conditions that trigger and control harmful algal blooms be sufficiently understood in order to predict occurrences and mitigate potential effects. The sampling stations marked on Figure 1 are located where the maximum taxonomic variability in phytoplankton community has been recorded.

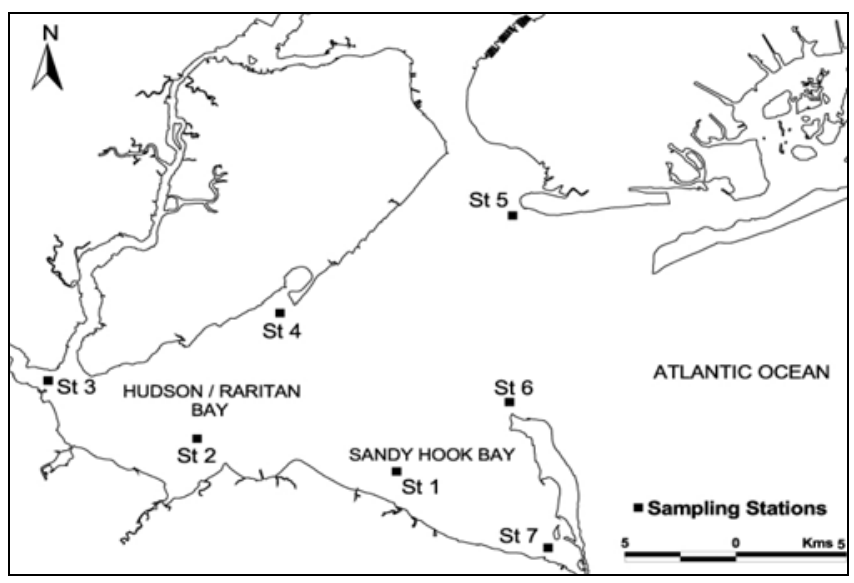

Figure 1. Map of study area with the locations of the sample points.

\section{Methods and Materials}

This paper validates AVIRIS data based on bio-optical forward/inverse modeling and building on the methods developed and reported earlier (Bagheri et al., 2005). The high spec- tral and radiometric resolution of the AVIRIS data allows discrimination of suspended sediments, by using spectral bands in which scattering is dominant, and phytoplankton blooms, by parameterization of the pigment induced reflectance minima since suspended sediments and phytoplankton blooms are frequently encountered in estuarine/coastal waters. Bio-optical models have been developed for analytical modeling of reflectance as a function of phytoplankton, CDOM and tripton or total suspended material (TSM). Remote measurements of reflectance/radiance are used for extraction of absorption/concentration of water quality parameters as outlined in the flowchart (Figure 2).

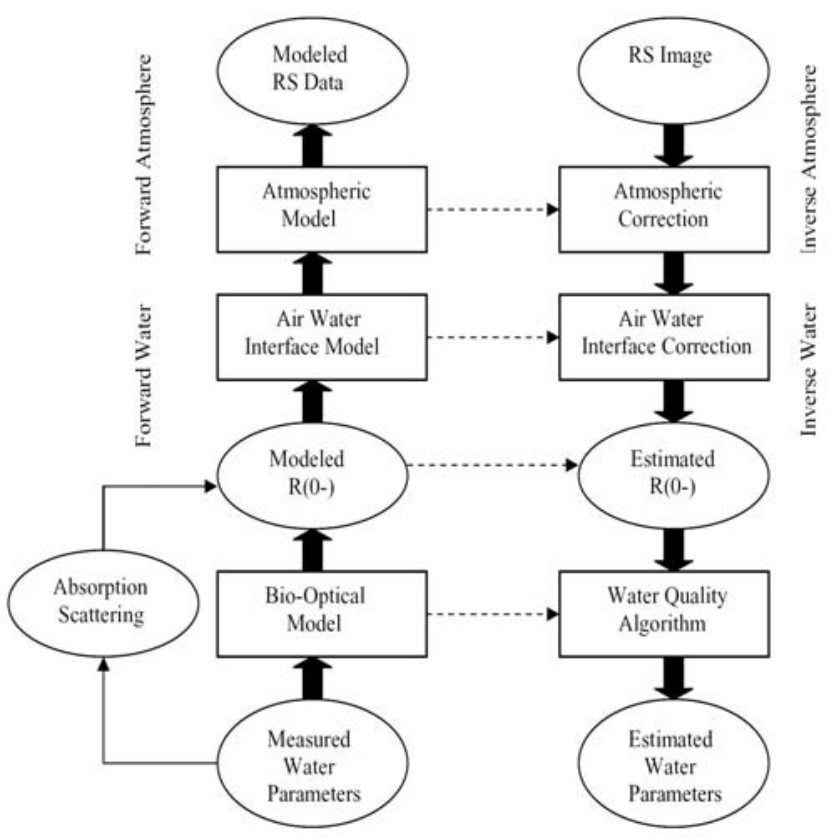

Figure 2. Forward and inverse modeling for remote sensing water quality (Dekker et al., 1997).

\subsection{Research Materials}

Data characteristics of AVIRIS, field spectroradiometer and the water sampling utilized for this study are briefly described below. In-situ measurements (i.e. shipboard samplings and optical measurements) were coordinated during the time period encompassing the AVIRIS data acquisition on July 13, 2001 (Detailed description can be found in Bagheri et al., 2005).

\subsubsection{Airborne Visible Infrared Imaging Spectrometer (AVIRIS)}

The AVIRIS sensor images the Earth's surface in 224 spectral bands approximately $10 \mathrm{~nm}$ wide covering the region 400 to 2,500 $\mathrm{nm}$ from a NASA ER-2 aircraft at an altitude of 20 $\mathrm{km}$. The ground resolution is $20 \mathrm{~m} \times 20 \mathrm{~m}$. AVIRIS sensor records the integrated effects of the solar source, the atmosphere and the targeted surface. The AVIRIS is capable of measuring hydrologic optical properties at a level of detail unmatched by 
any existing satellite instrument. (Note: All of the sensors' parameters are matched with the global positioning system (GPS) to establish correlation with spatial locations of sample points to be used for image registration and input into GIS).

\subsubsection{Field Spectroradiometer}

OL 754 is a scanning and submersible spectroradiometer, which makes spectral measurements from $300 \mathrm{~nm}$ to $850 \mathrm{~nm}$ at wavelength resolutions from $1 \mathrm{~nm}$ to $10 \mathrm{~nm}$ for computation of normalized percentage reflectance curves. Measurements of up and downward light fields and associated parameters (fraction of diffuse skylight etc.) were used to establish the relationship between inherent optical properties and the concentrations of water constituents within the water column.

\subsubsection{Shipboard Sampling}

Discrete shipboard samplings were collected along designated sampling stations (Figure 1). A hydrolab was used to obtain measurements of physical/chemical parameters (i.e. salinity, temperature and conductivity). Water was sampled for spectral absorption/scattering and concentrations of chlorophyll-a, particulate and color dissolved organic materials as described below.

\subsection{Research Methods}

Understanding the relationship between reflectance, absorption and backscattering of water is essential for developing the analytical algorithms necessary to use remote sensing as a management tool in the estuarine/coastal environment. The field measurements were comprised of in-situ measurement of $R(0-)$, IOP and concentrations of water quality parameters to characterize the inherent optical properties (IOPs) of the estuary. The IOP (absorption and backscattering) is physically related to subsurface irradiance reflectance $R(0-)$. $R(0-)$ links the optical properties to the water signals recorded by AVIRIS. In Case 2 waters, backscattering from particles and absorption by CDOM, algae and particulate matter affect the IOP.

\subsubsection{Subsurface Irradiance Reflectance $R(0-)$}

Subsurface irradiance reflectance $R(0-)$ as a ratio of upwelling to downwelling irradiance for all stations were obtained using the submersible field spectroradiometer (Bagheri et al., 2000). The goal was to parameterize the bio-optical model relating the colored dissolved organic matter (CDOM), tripton or total suspended matter (TSM) and algal pigment concentrations (Total CHL), to the light absorption and scattering and to the water leaving radiance, through direct and laboratory based optical measurements. In short, the link between remotely sensed upwelling radiance and underwater inherent optical properties is made through $R(0-)$ (Dekker, 1993).

\subsubsection{Inherent Optical Properties (IOP)}

The spectral absorption (a) and backscattering (b) are the inherent optical properties (IOP). The spectral absorption cau- ses reduction in $R(0-)$ and the spectral scattering causes an increase in $R(0-)$. Laboratory based spectrophotometric measurements of spectral attenuation (c) and spectral absorption was performed. From these measurements, the spectral scattering (b) was deduced via subtraction of spectral absorption from the spectral beam attenuation $(b=c-a)$. Absorption spectra of seston (phytoplankton and TSM) and tripton or TSM (suspended particles excluding phytoplankton) were determined using the filterpad method (Truper and Yentsch, 1967) with $0.45 \mu \mathrm{m}$ Whatman GF/F filters. The absorption was calculated on a basis of a calibrated relationship between the optical density of a suspension in a sample cell and the optical density on a filter (Weidemann and Cleveland, 1993). The absorption spectra of CDOM and the seston beam attenuation were determined spectrophotometrically according to the methods described in Rijkeboer et al. (1998).

\subsubsection{Water Quality Parameters (WQP)}

To estimate optical water quality concentrations coinciding with the spectral reflectance measurements, subsurface water samples ( 0.2 to $0.5 \mathrm{~m}$ depth) were collected in 1-1 bottles for laboratory analysis. Standard procedures as described by Rijkeboer et al. 1998 was used to determine the concentrations of total chlorophyll (TCHL) defined as the sum of chlorophyll-a and phaeopigment (as indication of concentration of phytoplankton) and total suspended matter (TSM). The TCHL and TSM concentrations were determined according to the Dutch standard norm (NEN 6520, 1981 and NEN 6484, 1982) respectively. Samples were also analyzed for identification and enumeration of the phytoplankton species to demonstrate the variety and composition of phytoplankton populations for input into library spectra of the estuary (Bagheri et al., 1999).

\subsection{Forward/Inverse Modeling}

The presence of several non-correlated constituents makes coastal/estuarine (Case 2) waters optically complex than most oceanic (Case 1) waters. The color of Case 1 waters quantified by the spectral subsurface irradiance reflectance, $R(0-)$, is predominantly a function of absorption and scattering by algal pigments, algal detritus and water itself. In Case 2 waters, backscattering from particles is the dominant scattering factor. In those waters the combined effects of particulate backscattering and high absorption introduce complex interacting relations between the water constituents and subsurface reflectance. Therefore, retrieval of constituent concentrations from the reflectance requires an analytical approach (Doerffer, 1989). In the analytical approach the retrieval is based on a bio-optical model which describes the relation between the reflectance and the concentrations of the constituents. To develop analytical algorithms for Case 2 waters, an optical (forward) model needs to link the WQPs to the IOPs, linking these in turn to the subsurface irradiance reflectance $(R(0-)$ for retrieval of constituent concentrations in (inverse) model as outlined in Figure 2 (Dekker et al., 1994). The measurement of $R(0-)$ is therefore the key modeling parameter for deriving water constituents in terms of total chlorophyll, colored dissolved 
organic matter and total suspended matter from atmospherically corrected remote sensing data (Kirk, 1994; Dekker et al., 1997).

\subsubsection{Forward Model}

Several optical models for ocean, coastal, and inland waters were investigated by Gordon et al., (1975), Morel and Prieur (1977), Whitlock et al., (1981), Kirk (1991), and Dekker et al., (1994). A simple optical water quality model based on the work of Gordon (1975) was calibrated for measurements of optical water constituent concentrations and inherent optical properties:

$$
R(0-)=r\left(b_{b} /\left(a+b_{b}\right)\right)
$$

where $a$ is total absorption coefficient; $b_{b}$ is backscatter coefficient; and $r$ is a factor based on the geometry of incoming light and volume scattering in the water.

To establish values for $r$ and $b_{b}$ for a specific location, knowledge of the volume scattering function is required. Vos et al. (1998) demonstrated that a practical solution for measurement of the volume scattering function is to estimate $r$ and $b_{b}$ by matching modeled $R(0-)$ to measured $R(0-)$ values. According to Kirk (1991), the factor $r$ for a large number of water bodies measured varied between 0.34 and 0.39 depending on the solar zenith angle and atmospheric conditions. Dekker et al. (1997) reported that the $r$ values ranged from 0.12 to 0.56 with an average of 0.29 for four inland water types in the Netherlands. In this study, the values for factor $r$ varied between 0.30 to 0.38 and were based on the field data obtained in the estuary during the course of the project and calculations made by fitting measured $R(0-)$ spectra to measured inherent optical properties. The inherent optical properties $a$ and $b_{b}$ were assumed to be linear functions of the constituent concentrations. This allowed the specific inherent optical properties (SIOP) to be introduced that link the concentrations of all optically active components to the subsurface irradiance reflectance. The inherent optical properties per unit concentration, e.g. the specific inherent absorption by phytoplankton, $a_{\text {ph }}^{*}$, was the absorption caused by $1 \mathrm{mg} \cdot \mathrm{m}^{-3}$ CHL. Using Beer's law, the total absorption coefficient $-a$, can be written as sum of the absorption by phytoplankton, TSM, CDOM, and water. The concentrations of the constituents are given by CHL, TSM, and $\mathrm{CDOM}_{440}$ (note that the CDOM absorption measured at $440 \mathrm{~nm}$ was taken as measure of concentration). The values for absorption coefficient $\left(a_{w}\right)$ and the scattering coefficient $\left(b_{w}\right)$ of pure water were taken from Bukata (1995).

The backscattering $\left(b_{b}\right)$ is used here which is based on the conversion of the scattering coefficient to the backscattering coefficient. This ratio depends directly on the volume scattering function (Pastercamp et al., 2000) and was estimated by means of optimization technique. Thus the volume scattering function of Petzhold (Kirk, 1994) is assumed to be valid, therefore $b_{b}$ was obtained as $0.019 b$. For pure water, this ratio is 0.5 but for seston measurements depends on the composition of the water (Morel and Prieur, 1977).

$$
\begin{aligned}
& a=a_{w}+a_{\mathrm{TSM}}^{*} \cdot \mathrm{TSM}+a_{p h}^{*} \cdot \mathrm{CHL}+a_{C D O M}^{*} \cdot \mathrm{CDOM}_{440} \\
& b_{b}=0.5 \cdot b_{w}+b_{b \mathrm{TSM}}^{*} \cdot \mathrm{TSM}
\end{aligned}
$$

where $a_{w}$ is absorption of pure water; $b_{w}$ is scattering of pure water; $a_{p h}^{*}$ is specific absorption of the phytoplankton; $b_{b \text { TSM }}{ }^{*}$ is specific backscatter of TSM; $a_{\mathrm{TSM}}^{*}$ is specific absorption of TSM; 0.5 is backscatter to scatter ratio of pure water; $a_{\mathrm{CDOM}}^{*}$ is specific absorption of CDOM; the asterisks $\left(^{*}\right)$ denote that $a$ and $b_{b}$ are specific inherent optical properties per unit concentration denoted by the subscript.

The next step was to parameterize the bio-optical model by relating concentrations of colored dissolved organic matter (CDOM), total suspended matter (TSM) and algal pigment concentrations to light absorption and scattering. The absorption and scattering coefficients of the main water quality parameters collected for all stations were averaged to produce a set of representative values and were used as input for calculating $R(0-)$. Figure 3 depicts that the chlorophyll spectra as the representative of phytoplankton biomass has two major absorption peaks, a blue maximum near $440 \mathrm{~nm}$ and a red maximum centered at 665 where in this study as in most cases, the blue peak is about two times greater than the red, and has been used in bio-optical modeling (Mobley, 1994). There is a trough near $550 \mathrm{~nm}$ in which absorption of all photosynthetic pigments is minimal (Bukata, 1995). The average spectral scattering showed slight decrease toward the longer wavelength.

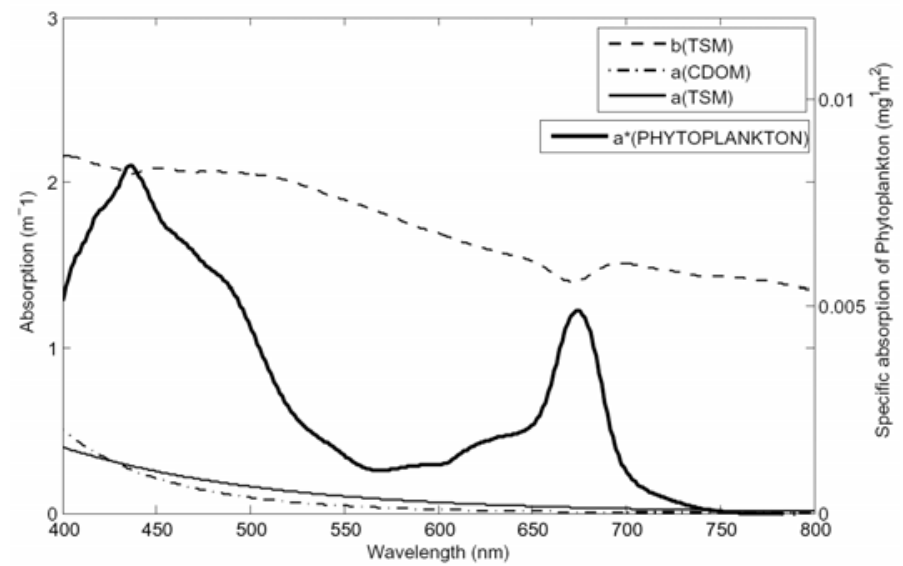

Notes: Left axis $=$ average absorption of CDOM and TSM and scattering of TSM; Right axis = specific absorption of Phytoplankton.

Figure 3. Average inherent optical properties of Hudson/Raritan Estuary for all stations sampled and marked on Figure 1.

Using the bio-optical model $R(0-)$ spectra were simulated for the measured concentrations (using measured IOPs). The subsequent comparison between simulated and measured $R(0-)$ provides a means to validate the bio-optical model and its accuracy as compared with the $R(0-)$ measurements recorded by the field spectroradiameter. In short, the link between remotely sensed upwelling radiance and underwater inherent optical 
properties is made through subsurface irradiance reflectance $R(0-)$. Figure 4 shows spectra for Shrewsbury River sampling location (St7 on Figure 1) comparing the measured $(R(0-)$ and modeled $R(0-)$. As demonstrated, there is a reasonable fit between calculated and measured $R(0-)$ spectra using bio optical model.

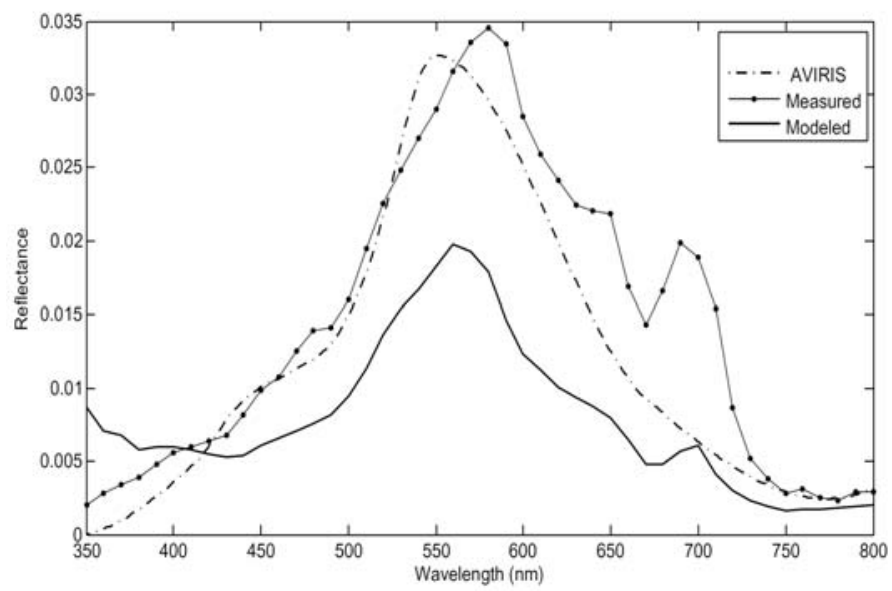

Figure 4. Comparisons of modeled $\mathrm{R}(0-)$ and measured (in water) $\mathrm{R}(0-)$ using OL754 spectroradiometer with atmospherically corrected AVIRIS spectra for Shrewsbury River (St 7 on Figure 1).

\subsubsection{Inverse Modeling}

To retrieve the concentrations of water quality parameters quantitatively, several inverse modeling algorithms (Hoge and Lyon, 1996; Hoogenboom et al., 1998; Peters, 2001) were applied to the data set of the study area. The linear matrix inversion model developed by Hoge et al. (1996) was selected which describes the generation of upwelled water leaving spectral radiance caused by backscatter and absorption of incident downwelling solar irradiance. This model is based on bio-optical model developed by Gordon et al. (1988):

$L_{w}(\lambda)=F_{0} \cdot t\left(\theta_{0}\right) \cdot \cos \left(\theta_{0}\right) \cdot M \cdot R / Q$

where $L_{w}$ is water-leaving radiance; $F_{0}$ is extraterrestrial solar irradiance; $t$ is diffuse transmittance of the atmosphere; $\theta_{0}$ is solar zenith angle; $M$ is 0.55 for nominal sea conditions; $R$ is measured reflectance at sample points; $Q$ is ratio of the upwelling radiance to upwelling irradiance toward zenith.

Gordon et al. (1988) have determined that $R / Q$ can be directly related to the total absorption $a$ and the total backscatter $b_{b}$ by $R / Q=\left(l_{1} X+l_{2} X^{2}\right)$, where $R=E_{u} / E_{d}, E_{u}$ and $E_{d}$ are the upwelling and downwelling irradiances, respectively, just beneath the surface. $Q$ is the ratio of the upwelling radiance to the upwelling irradiance toward zenith, $l_{l}=0.0949$ and $l_{2}=0.0794$ were calibrated as constants parameters (Gordon et al., 1988) and $X=b_{b} /\left(a+b_{b}\right)$.

The inversion matrices are used for solving for three unknowns $a_{p h}\left(\lambda_{1}\right), a_{d}\left(\lambda_{1}\right)$ and $b_{b t}\left(\lambda_{1}\right)$ at any wavelength $\lambda_{i}$ :

$$
\left[\begin{array}{ccc}
1 & 1 & v\left(\lambda_{1}\right) \\
D_{21} & e^{\left[-S\left(\lambda_{2}-\lambda_{1}\right)\right]} & \left(\lambda_{1} / \lambda_{2}\right)^{n} v\left(\lambda_{2}\right) \\
D_{31} & e^{\left[-S\left(\lambda_{3}-\lambda_{1}\right)\right]} & \left(\lambda_{1} / \lambda_{3}\right)^{n} v\left(\lambda_{3}\right)
\end{array}\right] \cdot\left[\begin{array}{c}
a_{p h}\left(\lambda_{1}\right) \\
a_{d}\left(\lambda_{1}\right) \\
b_{b t}\left(\lambda_{1}\right)
\end{array}\right]=\left[\begin{array}{c}
h\left(\lambda_{1}\right) \\
h\left(\lambda_{2}\right) \\
h\left(\lambda_{3}\right)
\end{array}\right]
$$

where $\mathrm{h}(\lambda)=-\left(a_{w}+b_{b w} v\right) ; a_{w}$ is absorption coefficient of pure water; $b_{b w}$ is backscatter coefficient of pure water; $\lambda$ is different wavelengths; $s$ is spectral slopes; $n$ is total constituent backscattering spectral exponent; $g$ is phytoplankton Gaussian model spectral width; $a_{p h}$ is absorption coefficient of the phytoplankton; $a_{d}$ is absorption coefficient of CDOM; $b_{b t}$ is total constituent backscattering coefficient; $V$ is a factor to separate absorption and scattering components of water; $D_{21}=e^{\left(\lambda_{2}-\lambda_{1}\right)^{2} /\left(-2 g^{2}\right)}$; $D_{31}=e^{\left(\lambda_{3}-\lambda_{1}\right)^{2} /\left(-2 g^{2}\right)}$.

The $a_{p h}\left(\lambda_{i}\right), a_{d}\left(\lambda_{i}\right)$ and $b_{b t}\left(\lambda_{i}\right)$ at all wavelengths are computed using the following:

$$
\begin{aligned}
& a_{p h}\left(\lambda_{i}\right)=a_{p h}\left(\lambda_{g}\right) \cdot e^{\left[\left(\lambda_{i}-\lambda_{g}\right)^{2} /\left(-2 g^{2}\right)\right]} \\
& a_{d}\left(\lambda_{i}\right)=a_{d}\left(\lambda_{d}\right) \cdot e^{\left[-s\left(\lambda_{i}-\lambda_{g}\right)\right]} \\
& b_{b t}\left(\lambda_{i}\right)=b_{b t}\left(\lambda_{b}\right)\left(\lambda_{b} / \lambda_{i}\right)^{n}
\end{aligned}
$$

To calibrate the model, the algorithm was applied to the in water measurements collected by the field spectroradiometer in the estuary to retrieve the IOPs (from which the constituent concentrations were obtained). Using the following, the concentration was obtained from the specific absorptions of water quality parameters (i.e. TCHL):

$$
C=a_{p h}\left(\lambda_{1}\right) / a_{p h}^{*}\left(\lambda_{1}\right)
$$

where $a_{p h}^{*}\left(\lambda_{1}\right)$ is the chlorophyll-specific absorption at $\lambda_{1}$.

The result of the matrix inversion method for calculating TCHL concentration is shown in Figure 5 with the following values for: $\lambda_{1}=430, \lambda_{2}=500, \lambda_{3}=560 \mathrm{~nm}, S=0.025, n=1.2$, $g=30$.

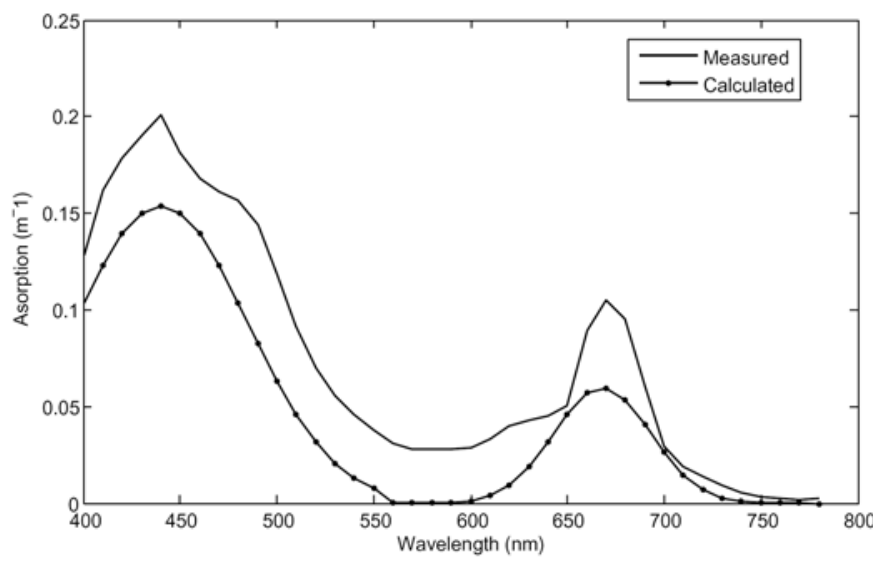

Figure 5. Measured and retrieved absorptions of phytoplankton at Great Kills (St 4 on Figure1) using the linear matrix inversion method (Hoge et al., 1996). 
Table 1. Total Chlorophyll and Total Suspended Matter vs. Field Measurements

\begin{tabular}{lccccc}
\hline Station & $\begin{array}{c}\text { Measured TCHL } \\
\left(\mathrm{mg} / \mathrm{m}^{3}\right)\end{array}$ & $\begin{array}{c}\text { Modeled TCHL(\#1) } \\
\left(\mathrm{mg} / \mathrm{m}^{3}\right)\end{array}$ & $\begin{array}{c}\text { Modeled TCHL(\#2) } \\
\left(\mathrm{mg} / \mathrm{m}^{3}\right)\end{array}$ & $\begin{array}{c}\text { Measured TSM } \\
\left(\mathrm{g} / \mathrm{m}^{3}\right)\end{array}$ & $\begin{array}{c}\text { Modeled TSM(\#2) } \\
\left(\mathrm{g} / \mathrm{m}^{3}\right)\end{array}$ \\
\hline Traid Bridge & 17 & 15 & 9 & 13 & 16 \\
Crookes Pt Staten Isl. & 37 & 22 & 74 & 6 & 8 \\
Coney Isl. Pt. & 15 & 12 & 12 & 26 & 22 \\
Sandy Hook Tip & 32 & 17 & 12 & 19 \\
\hline
\end{tabular}

* Retrival of TCHL (\#1) is based on matrix inversion model developed by Hoge et al. (1996) and detailed in this paper. Retrieval of TCHL and

TSM concentrations (\#2) are based on matrix inversion model developed by Hoogenboom et al. (1996) and described in Bagheri et al. (2005).

Table 1 compares the results of two retrieval methods (Hoge et al., 1996 and Hoogenboom et al., 1998) to the dataset quantitatively and Figure 6 demonstrates the correlation between the measured and retrieved chlorophyll concentrations based on the inverse modeling used. Both Table 1 and Figure 6 demonstrate a good match between the insitu measurements and the retrieved water constituents (TCHL and TSM) concentrations. Validation of the concentration estimates by optical means is based on in situ measurements of spectra and concentrations. The description for the Hoogenboom et al. (1998) inversion technique is not included here and it is used for the purpose of comparison. The details can be found in Bagheri et al. (2005).

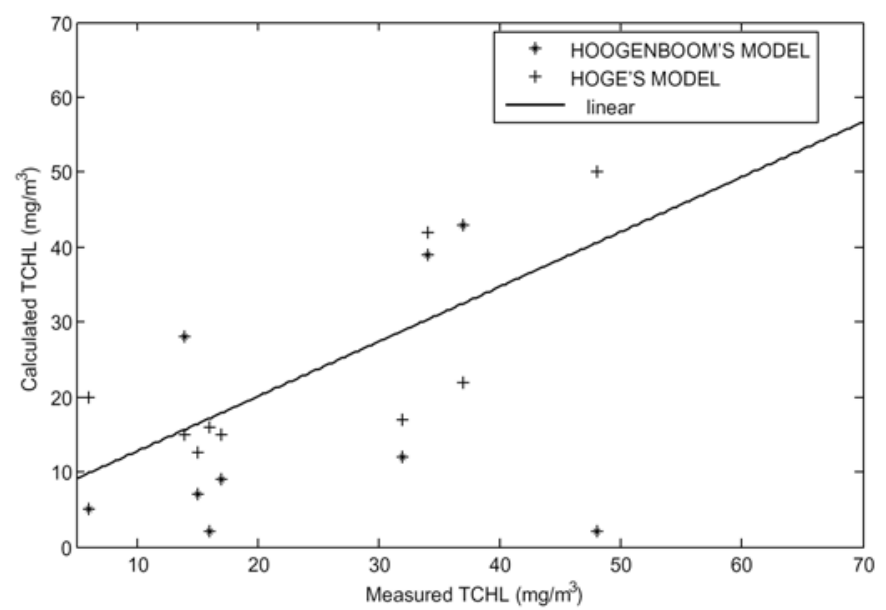

Figure 6. Comparison of measured and calculated TCHL concentration using matrix inversion methods by Hoge et al. (1996) and Hoogenboom et al. (1998).

\subsubsection{AVIRIS Data Analysis}

To use remote sensing and geographic information systems (GIS) technologies as effective tools in monitoring and management of water resources, it is essential to provide the managers and planners with adequate water quality information from remote sensing data at the right times and in the right formats. Thus it is required to develop methodology for processing the remote sensing data to desired water quality parameter maps. Such maps can be disseminated over the WWW (Internet) for input into GIS as integral part of the estuarine water quality database for comprehensive management of water resources.

As part of such efforts, the AVIRIS data spectrally and radiometrically were calibrated to radiance/reflectance for biooptical modeling and generation of thematic maps of water quality parameters using a radiative transfer model-MODTRAN4. MODTRAN is a radiative transfer code developed by US Air Force Geophysical Laboratory which describes the radiative transfer process in the entire system from the solar source to the remote sensor via the hydrosols (Berk et al., 1989). The MODTRAN model simulates the radiance observed by a given senor-pixel-sun geometry at a given altitude for a given surface albedo. The atmosphere in MODTRAN was characterized by a midlatitude summer atmospheric model with horizontal visibility of $20 \mathrm{~km}$ (Bagheri et al., 2005). As outlined in Fgure 2, the inversion of such a model can be used to characterize the estuarine waters in terms of total chlorophyll, colored dissolved organic matter and total suspended matter from the observed spectra using AVIRIS image data. The result of the MODTRAN application on atmospherically corrected AVIRIS spectra is also included in Figure 4 - spectra for Shrewsbury River sampling location. Again Figure 4 shows that a reasonable fit was obtained between the calculated $R(0)$ spectra from the AVIRIS image data and the bio-optical model simulated data (model $R\left(0^{-}\right)$) and measured $R\left(0_{-}\right)$.

To generate water quality thematic map, band ratio technique was applied to a three-component bio-optical model, which was parameterized using IOPs of Hudson/Raritan estuarine waters. The AVIRIS derived chlorophyll map (band ratio) was compared and validated with chlorophyll in situ data, collected during the AVIRIS overflight. Figure 7 depicts the spatial distribution of chlorophyll concentration as band ratio of the AVIRIS atmospherically corrected data over the southern portion of the study area. AVIRIS depicts chlorophyll concentration range between $0 \mathrm{mg} / \mathrm{m}^{3}$ and $>50 \mathrm{mg} / \mathrm{m}^{3}$ with maximum values in the southwestern portion of the estuary and at the confluence of the Raritan River with the estuarine water (Figure 7).

\section{Results and Discussions}

In our approach IOP of water constituents were used to model the reflectance. The chlorophyll concentrations were mapped using a physically-based approach which involved (i) the application of a forward model and (ii) the adoption of an inversion technique to estimate constituent concentrations. The 
matrix inversion method and band ratio applied to a threecomponent bio-optical model, which was parameterized using IOPs of Hudson/Raritan waters. Table 1 indicates that a reasonable fit was found between modeled and measured constituent concentrations using the optical model and the matrix inversion models. In this paper matrix inversion method was applied to the in-water measurements recorded by the field spectroradiometer to calibrate the model. The next step will be the application of the inverse modeling to atmospherically corrected AVIRIS data to further validate the utility of inverse modeling for retrieval of water quality parameters using remotely sensed data. We were able to closely match AVIRIS data flown over the Hudson/Raritan Estuary by simulation using a bio-optical modeling tool parameterized for the estuary. The AVIRIS derived chlorophyll map (band ratio) was compared and validated with chlorophyll in situ data, collected during the AVIRIS overflight (Figure 7). Most algorithms for deriving water constituent concentrations are empirically calibrated to a specific region and time and are based on relating either one channel or a ratio of two channels. Bio optical information (modeling) can be used to make algorithms for water quality parameters (TSM, CHL and CDOM) of semi analytical and analytical character. We used analytical algorithms (complete mathematical inversion of the bio-optical model) which require: a) simplified bio-optical model; b) the biooptical model has to be calibrated using small dataset of inherent optical properties, concentration and reflectance spectra. Analytical algorithms have the advantage that the processor can be build independent of the parameterization of dataset. This means that the algorithms can be easily adapted to other conditions and times. Essentially, analytical algorithms fit a simulated spectrum to measured spectrum, therefore they can be validated using concentration measurements or measured reflectance spectra. This work provides a reference baseline of remote sensing and insitu measurements that will have significance for future work on underwater light field and remote sensing methodology development for the Hudson/Raritan Estuary.

\section{Conclusion and Recommendation}

Atmospheric correction of ocean color imagery is commonly based on the assumption that the water-leaving radiances at NIR are negligible. Over the open ocean an aerosol model and aerosol optical depth can be derived from the NIR channels. The aerosol information can be extrapolated into the visible range for retrieval of the water leaving radiance and the estimation of the chlorophyll concentration. Unfortunately, these algorithms cannot be used in Case 2 waters because the suspended material in Case 2 waters has strong scattering in the NIR part of the spectrum. The AVIRIS is capable of measuring hydrologic optical properties at a level of detail unmatched by any existing satellite instrument. The AVIRIS hyperspectral data provide us with an opportunity to develop such algorithms based on the different spectral reflectances characterizing aerosol and water constituents. This can be used as a basis for distinguishing between atmospheric and oceanic effects and to set the estimated turbidity for each region within the image for retrieval of water constituents. Development of a robust algorithm for simultaneous retrieval of atmospheric aerosol optical properties, chlorophyll concentration and colored dissolved organic matter is a very challenging task. Nevertheless, such an algorithm is needed to make progress in this area. Using library spectra of different phytoplankton pigments we will explore the extent to which phytoplankton species differentiation can be retrieved. The library spectra can be used as a management tool for monitoring water resources and provides a baseline on the characteristics of algal blooms important in climate/global change studies.

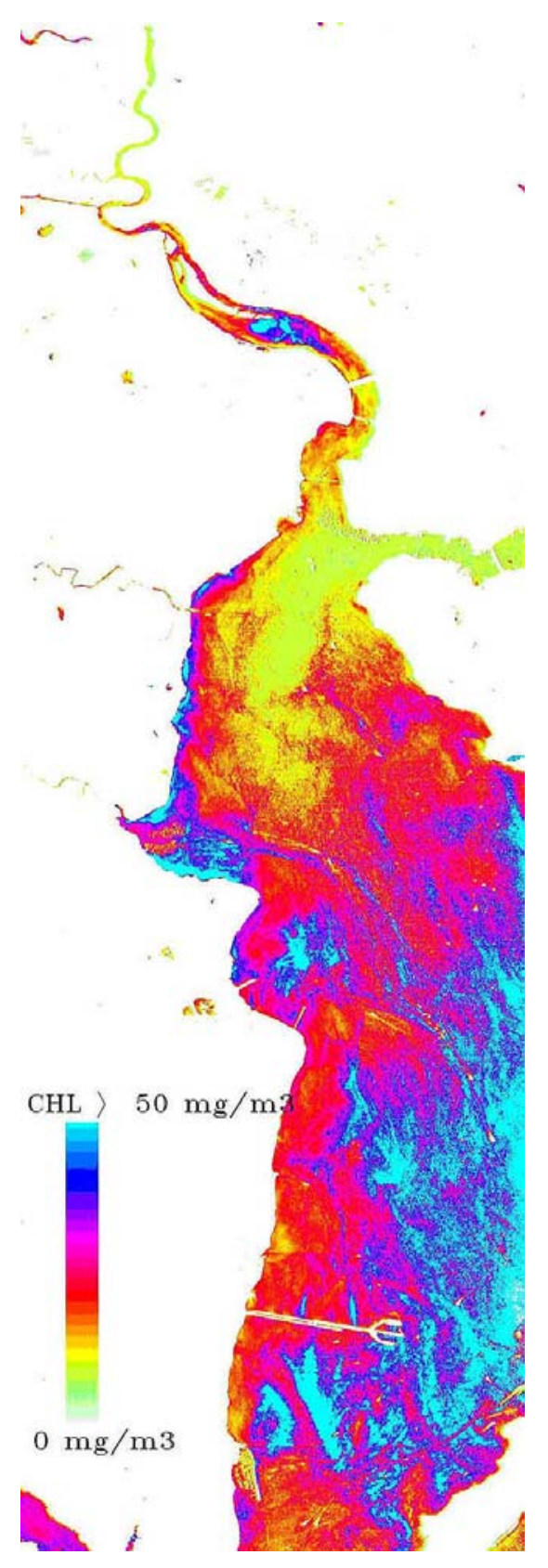

Figure 7. AVIRIS(702 nm/675 nm) band ratio map of total Chlorophyll (TCHL) concentration along the Raritan River. 
Acknowledgments. This project was funded by the National Science Foundation (BES-9806982). Support of the NASA Headquarters Ocean Biology/Biogeochemistry Program, and the AVIRIS Science Team is greatly appreciated.

\section{References}

Aguirre-Gomez, R., Boxal1, S.R. and Weeks, A.R. (1995). Identification of Algal Pigments Using High Order Derivatives, IEEE Pro- ceedings, pp. 2084-2086.

Bagheri, S., Peters, S. and Yu, T. (2005). "Retrieval of Water Quality Constituents Concentrations from AVIRIS data in Hudson/Raritan Estuary," Intl. J. Remote Sens., 26(18), 4013-4027, doi:10.1 080/01 43116042000274023.

Bagheri, S. and Peters, S.W.M. (2003). Retrieval of Marine Water Constituents Using Atmospherically Corrected AVIRIS Hyperspectral Data", 12th Aviris Workshop, JPL, Pasadena, CA.

Bagheri, S., Rijkeboer, M., Pasterkamp, R., and Dekker, A.G. (2000). Comparison of the Field Spectroradiometers in Preparation for Optical Modeling, 9th Aviris Workshop, JPL, Pasadena, CA.

Bagheri, S. and Dekker, A.G., (1999). Nearshore Water Quality Assessment Using Bio-Optical Modeling and Retrieval Techniques, Proceedings of the 8th NASA/AVIRIS Geoscience Workshop, JPL, Pasadena, CA.

.Berk, A., Berstien. L.S., and Robertson, D.C. (1989). MODTRAN: A moderate reolutionmodel for LOWTRAN7, Report GL-TR-890122, US Air Force Geophysical Laboratory, Hanscom, Massachusetts.

Bukata, R.P., Jerome, J.H., Konratyev, K. and Pozdnyakov, D.V. (1995). Optical Properties and Remote Sensing of Inland and Coastal Waters, CRC Press, Boca Raton.

Dekker, A.G. (1993). Detection of Optical Water Quality Parameters for Eutrophic Waters by High Resolution Remote Sensing, $\mathrm{PhD}$ Thesis, Vrije University, Amsterdam, pp. 222, ISBN: 90-9006234-3.

Dekker, A.G. and Donze, M. (1994). Imaging Spectrometry as a Research Tool for Inland Water Resources Analysis, J. Hill, Dordrecht, the Netherlands, Kluwer AP.

Dekker, A.G., Hoogenboom, H.J., Goddijn, L.M. and Malthus, T.J.M. (1997). The Relationship between Inherent Optical Properties and Reflectance Spectra in Turbid Inland Waters, Remote Sens. Rev., 15, 59-74.

Doerffer, R. (1989). Imaging spectroscopy for Detection of Chlorophyll and Suspended Matter, Imaging spectroscopy: Fundamentals and Perspective Applications, Kluwer AP, 215-258.

Gordon, H.R., Brown, O.B. and Jacobs, M.M. (1975). Computed Relationships Between Inherent and Apparent Optical Properties of a Flat Homogeneous Ocean, Appl. Optics, 14, 417-427.

Gordon, H.R., Brown, O.B., Evens, R.H., Brown, J.W., Smith, R.C., Baker, K.S. and Clark, D.K. (1988). A semi-analytic Radiance Mo- del of Ocean Color, J. Geophys. Res., 93, 10909-10924.

Hoge, F.E. and Lyon, P.E. (1996). Satellite Retrieval of Inherent Optical Properties by Linear Matrix Inversion of Oceanic Radiance Models: an Analysis of Model and Radiance Measurement Errors, J. Geophys. Res., 101(16), 631-648, doi:10.1029/96JC0 1414.
Hoogenboom, H.J., Dekker, A.G. and De Haan, J.F. (1998). Retrieval of Chlorophyll and Suspended Matter from Imaging Spectrometry Data by Matrix Inversion, Can. J. Remote Sens./J. Can. Teledetect., 24(2), 144-152.

Jeffries, H.P. (1962). Environmental Characteristics of Raritan Bay, a polluted estuary, Limnol. Oceangr., 7(1), 21-31, doi:10.1016/00 11-7471(63)90255-9.

Kirk, J.T.O. (1991), Volume Scattering Function, Average Cosines, and the Underwater Light Field, Limnol. Oceangr., 36(3), 455467.

Kirk, J.T.O. (1994). Light and Photosynthesis in Aquatic Ecosystems, Cambridge University Press, Cambridge, UK, pp. 401.

Mobley, C.D. (1994). Light and Water; Radiative Transfer in Natural waters, Academic Press, London, UK, pp. 592.

Morel, A and Prieur, L. (1977). Analysis of Variations in Ocean Color, Limnol. Oceanogr., 22, 709-722.

NEN 6520, (1981). Water: Spectrophotometric determination of chlorophyll a Content, Nederlands Normalisatie, instituut, Delft, The Netherlands (in Dutch).

NEN 6484, (1982). Water: Determination of the Content of Not Dissolved Material and its Ignition Residue, Nederlands Normalisatie, instituut, Delft, The Netherlands (in Dutch).

Oey, L.Y., Mellor, G.L. and Hires, R.I. (1985). A three-Dimensional Simulation of the Hudson/Raritan Estuary, Part I and II, Journal of Geophysical Oceanography, 15(12), 1676-1720.

Pastercamp, R., Peters, S.W.M. and Dekker, A.G. (2000). Environmental Baseline Mapping of Total Suspended Matter Concentrations in the Western Scheldt Estuary Supported by the SPOT Images, Proceedings of ERIM 6th Inter. Conference, Charleston, NC, pp. 260-267.

Pearce, J., (1988). Changing patterns of Biological Responses to Pollution in the New York Bight In: Hudson/Raritan Estuary Issues, Resources, Status and Management, NOAA Estuary of the month seminar, No. 9, pp. 1-26.

Peters, S.W.M. (2001). Analytical Inversion Methods for Water Quality Parameter Determination from Remotely Observed Spectra, Institute Environmental Studies, Vrije Universiteit, Netherlands.

Rijkeboer, M., Dekker, A.G. and Hoogenboom, H.J., (1998). Reflectance Spectra with Associated Water Quality Parameters Measured in Dutch waters (Speclib-TK-database), Institute for Environmental Studies, E98/12, The Netherlands.

Truper, H.G. and Yentsch, C.S. (1967). Use of Glass Fiber Filters for the Rapid Preparation of in Vivo Absorption Spectra of Photosynthetic Bacteria, J. Bacterial., 94, 1255-1256.

Vos, R.J., Dekker, A.G., Peters, S.W.M., Rossum, G.V. and Hooijkaas, L.C. (1998). RESTWAQ2, part II, Comparison of Rremote Sensing Data, Model Results and in-situ Data for the Southern Frisian Lakes, Rep.num. NRSP-2 98-08b, Netherlands Remote sensing Board (BCRS), Programme Bureau; Rijkswaterstaat Survey Department.

Weidemann, A.D. and Cleveland, J.S. (1993). Quantifying Absorption by Aquatic Particles: A Multiple Scattering Correction for Glass-Fiber Filters, Limnol. Oceanogr., 38, 1321-1327.

Whitlock, C.H., Poole, L.R., Usry, J.W., Houghton, W.M. and Witte, W.G. (1981). Comparison of Reflectance with Backscatter and Absorption Parameters for Turbid Waters, Appl. Opt., 20, 517522. 